\title{
Organic Agriculture as a Sustainable Solution to Chronic Kidney Disease Unidentified (CKDu)
}

\author{
Hemanthi Ranasinghe
}

Department of Forestry and Environmental Science, University of Sri Jayewardenepura, Sri Lanka

\begin{abstract}
Chronic Kidney Disease Unidentified (CKDu) is a rare form of tubule-interstitial disease involves slow, asymptomatic progressive kidney damage over 3 or more months, making diagnosis and treatment difficult. Nearly $80 \%$ of patients experience total kidney failure within 2 years following diagnosis. According to the Ministry of Health (2016) the total deaths due to renal failure had shown a decrease from 2,215 in 2011 to 2,147 in 2014. The total number of patients in the high risk areas have been recorded as 21,452. Over the past 12 years numerous studies have been undertaken by a range of institutions in relation to the problem and, as a result, a body of research has been established. While there is still considerable debate and conjecture over the causal factors contributing to the development of CKDu, there are facts supported by information that provide insights into the disease. Among the most significant causal factors, the long term exposure to contaminated (with heavy metals) drinking water accentuated by the natural hardness and fluoride content of the same, long term exposure to agrochemicals including sub optimal applications of them without wearing protective gear, occupations such as farming which includes long hours of exposure to the sun and agrochemicals, low socio economic status including income and education, lifestyle habits which include smoking, consumption of illicit liquor and microalbuminuria etc. had been documented by researchers. Resorting to organic agriculture which is a production system that sustains the health of soils, ecosystems and people, has been identified as a sustainable solution to the prevention/reduction of the disease. As most of the lands are under conventional farming a transition period is required. Among the most important factors which needs to be looked into in the context of organic farming, management of soil fertility, weed control, pest and disease control, farm animal integration and finally going for certification, regulation and standards are key. Despite numerous challenges to adopt organic agriculture country has been provided with a concerted directive and leadership in adopting this especially in the aftermath of the killer disease, CKDu. In this context the launching of the national programme titled 'Towards a Toxin Free Country' and a three year plan had been prepared to achieve this target are significant. A separate institution had been established under the President to coordinate these activities. This paper elaborates the methodologies to be adopted in this transition from inorganic to organic agriculture to achieve long term sustainability in agriculture and natural resources management sectors and also to effectively manage Chronic Kidney Disease unidentified in which long term exposure to agrochemicals had been identified as a significant causal factor.
\end{abstract}

KEYWORDS: Chronic Kidney Disease Unidentified, organic agriculture, agrochemicals, soil fertility, Toxin Free Country 


\section{INTRODUCTION}

\subsection{CKD and CKDu}

Chronic Kidney Disease (CKD), also known as Chronic Renal Disease, is the progressive loss in kidney function over a period of months or years. Often, Chronic Kidney Disease is diagnosed as a result of screening of people known to be at risk of kidney problems, such as those with high blood pressure or diabetes and those with a bloodline relative with CKD. However, the Chronic Kidney Disease Unidentified (CKDu) is not related to the known cause commonly identified with kidney disease such as diabetes, hypertension, obesity or other factors such as snake bite (Ministry of Healthcare and Nutrition, Epidemiology Unit, Sri Lanka and World Health Organization, 2009).

This rare form of tubule- interstitial disease involves slow, asymptomatic progressive kidney damage over 3 or more months, making diagnosis and treatment difficult. Nearly $80 \%$ of patients experience total kidney failure within 2 years following diagnosis. Given the inadequacy of medical services, the high cost of treatment such as dialysis and organ transplantation and the poverty of most victims, death becomes inevitable for most (Handunnetti \& Daniel, 2012).

With regards to the geographical distribution of the disease, the most number of CKDu patients have been reported from three provinces i.e., North Central Province, Uva Province and Eastern Province. Of this, high prevalence of CKDu patients were observed in the regions of North Central Sri Lanka, mainly in DS Divisions of Medawachchiya, Girandurukotte, Kabithigollawa, Padaviya, Medirigiriya, Dehiattakandiya and Nikawewa regions (IWMI, 2012). According to the Ministry of Health (2016) the total deaths due to renal failure had shown a decrease from 2,215 in 2011 to 2,147 in 2014. The total number of patients in the high risk areas have been recorded as 21,452.

\subsection{Possible causative factors of the disease}

Over the past 12 years numerous studies have been undertaken by a range of institutions in relation to the problem and, as a result, a body of research has been established. They range from hospital cohort and community level studies, water resource studies, assessments of food sources, and studies into possible genetic linkages. While there is still considerable debate and conjecture over the causal factors contributing to the development of $\mathrm{CKDu}$, there are facts supported by information that provide insights into the disease. Among the most significant causal factors, the long term exposure to contaminated (with heavy metals) drinking water accentuated by the natural hardness and fluoride content of the ground water, long term exposure to agrochemicals including sub optimal applications of them without wearing protective gear, occupations such as farming which includes long hours of exposure to the sun and agrochemicals, low socio economic status including income and education, lifestyle habits which include smoking, consumption of illicit liquor and microalbuminuria etc. had been documented by researchers. There is a growing body of knowledge that would suggest a genetic link to the problem that predisposes certain individuals to the disease (IWMI, 2012).

\section{2. CONTRIBUTION OF AGROCHEMICALS TO THE ONSET OF CKDu}

Rajarata, home to the CKD tragedy, was the seat of the ancient hydraulic civilization and is still the "rice bowl" of the island producing much of its staple food. A vast interconnected irrigation system of reservoirs and canals formed the basis of the prosperous economy and the Rajarata culture (Bandarage, 1993). Even after the demise of the dry zone civilization in $12 \mathrm{AD}$ and the shift of populations to the wet zone, the farmer remained the backbone of the society and rice cultivation the occupation of the largest 
segment of the population. However, now, $\mathrm{CKDu}$ is decimating the bearers of the noble occupation who amid enormous hardship and suffering continue to till the land to feed the country.

The "Green Revolution" using "miracle" hybrid varieties of seeds and dependent on extensive use of agrochemicals including fertilizers, hormones, soil treatments, and pesticides was introduced to Sri Lanka in the 1970s. Agrochemicals that enhance crops began to be used extensively in Sri Lanka's plantation and traditional agricultural sectors with the introduction of the "Open Economy" and import liberalization in 1977. Between 1983 and 1997, the quantities of formulated pesticides (insecticides, herbicides, and fungicides) imported increased tenfold (Sim, 1989; Taylor, 1999 reported in IWMI, 2012). While imports leveled off in subsequent years, increasing commoditization and industrialization of agriculture kept pesticide use at high levels. Pesticide use has been particularly heavy in the Mahaweli Development Program and in the North Central Province in general (Udyanganie et al., 2006 in IWMI, 2012). Graeme Taylor who conducted a field study of pesticide use in the Mahaweli $\mathrm{H}$ area in 1999 noted that $89 \%$ of paddy cultivated areas were chemically weeded. New strains of rice have been produced that are more responsive than traditional varieties to inputs of fertilizers, leading to improved yields. However, increased fertilizer inputs will also result in increased weed growth, so herbicides are commonly applied throughout the crop cycle. (Taylor, 1999 reported in IWMI, 2012).

A study published in 2009 by Rohana Chandrajith and a team of Sri Lankan scientists reported that paddy soils in areas experiencing rapid economic development are polluted with potentially toxic metals. The study observed widespread application of phosphate fertilizers with uranium and other elements known for their nephrotoxic effects: The paddy soils in Sri Lanka are highly modified by artificial fertilizer applications. During the period of waterlogging in rice cultivation, the chemical nature of the soil can be drastically changed and pollutants can be leached easily into subsurface, which eventually contaminate the ground water that rural people use as a drinking water source. (Chandrajith et al., 2010)

In Sri Lanka, where rice is cultivated in two seasons per year, fertilizers tend to be applied 3 times every season. According to Chandrajith et al (2010) despite the fact that the recommended amount of application is $270 \mathrm{~kg}$ per hectare of fertilizers such as urea, triple phosphate (TSP), and potash per season over the past few decades, their application has increased by more than double the recommended levels. They attributed this to massive increase in fertilizer subsidies granted by the government and the use of "very low quality" imported fertilizer due to "the unavailability of a proper controlling mechanism" (Chandrajith et al., 2010). The search for causes of the CKD epidemic necessitates consideration of the bio-medical as well as the ecological and political-economic dimensions of agrochemical use.

\section{ORGANIC AGRICULTURE AS A SUSTAINABLE SOLUTION TO COMBAT THE DISEASE}

Organic Agriculture is a production system that sustains the health of soils, ecosystems and people. It relies on ecological processes, biodiversity and cycles adapted to local conditions, rather than the use of inputs with adverse effects. Organic agriculture combines tradition, innovations and science to benefit the shared environment and promote fair relationships and good quality of life for all involved (Lanka Organic Agriculture Movement). Its suitability can be depicted by maintaining the balance of bio diversity, elimination of artificial agrochemicals, use of hygienic foods, identifying the importance of soil sustainability, reduce fossil fuel combustion etc. Organic agriculture can also play a significant role in reducing the atmospheric 
carbon dioxide concentration by retaining excess carbon in the soil as organic matter.

\subsection{Transition to organic farming}

As most of the lands are under conventional farming today it is a general concern that almost all the cultivated soils are polluted and cannot be used for organic farming. It needs a certain time period to achieve the level of organic farming from a conventional farming land. This period can be identified as a transition period.

\subsection{Management of soil fertility}

Major focus of organic farming is to develop the soil fertility, maintain the stability and sustainability of the farming system. Plant requirements vary according to the crop type. Therefore, it is essential to select crops according to the soil characters. In general the following requirements need to be met in order to keep the fertility of the soil optimal; soil should not be exposed to direct sun light or severe rainfall. This can be achieved by covering the crops using green manure and leaf litter and by growing cover crops. Mixed cropping helps to maintain the sustainability of soil fertility by minimizing possible inter seasonal and intra seasonal imbalances.

Organic fertilisers and incorporation of organic matter to the soil will enhance soil fertility and improve the quality of soil too. When organic matter is incorporated to the soil they decay and turn in to structures which cannot distinctly be identified. These are dark brown or black in colour and parts of them make the substance called humus which is very important for the fertility of the soil. Farm yard manure, compost, leaf litter, plant extract etc. can be taken as fertilizers.

These can simultaneously possess soil stabilizing and pest controlling abilities. All these are very important organic inputs composed of significant amount of soil nutrients. Mixing and integration of these will lead to use much balanced fertilizers. As these compounds increase the amount of soil organic matter they will maintain the fertility and sustainability of the soil. Land preparation methods need to be selected to minimize soil compaction and erosion. Proper tillage and irrigation will facilitate drainage and aeration (Ranasinghe, 2016).

\subsection{Weed Control}

Common weed controlling methods in an organic farm are, mulching (both live and dead), crop rotation, use of balanced fertilizer, use of minimal land preparation, hand weeding before the weed reaches reproductive stage, use of seeds without weed seeds, hand weeding or use of simple machinery and use of properly matured compost (Ranasinghe, 2016).

\subsection{Pest and Disease Control}

As it is strictly prohibited to use agrochemicals for pest control in organic farming, a farmer should always follow biological control, manual methods or plant extracts. Following are some of such methods used in organic farming; use of selected resistant varieties, establishment of farming systems to encourage symbiotic biological control, use of balanced fertilizer, maintenance of appropriate moisture levels through appropriate water management, preservation and promotion of natural enemy populations, selection of suitable cropping season and space, selective removal of diseased plants, seeds treatments using natural extracts, use of natural pesticides such as plant extracts and hand removal and setting traps (Ranasinghe, 2016).

\subsection{Farm Animal Integration}

This is an essential component in organic farming. Animals play vital role in recycling of organic matter. Such procedures are essential components of almost all traditional farming methods (Lanka Organic Agriculture Movement). 


\subsection{Certification, regulation and standards and consumer awareness}

Certification, regulation and standards were originated with the global extension of organic agriculture. Reason for this is the increased distance between the organic product consumers and farmer. The consumer may live in distant places within a country or different countries. Therefore, the consumer's attention to an organic product can only be obtained if it is certified by different certification bodies based in different countries. It is also important to obtain a certification to market those products. The certified body add their particular certification mark on the label of the product. Such bodies are functioning in different countries and they are globally accepted with their labels. In order to obtain this certification label farmer should maintain his farm according to the regulations mentioned previously. The certification body will provide the farmer with information on the aspects they consider when giving a certification.

This is a similar process to the quality certification, "SLS" provided for the Sri Lankan product. SLS is perceived as a certification by the consumer. Similarly, organically certified labels provide a certification to the consumer. There are number of producers in Sri Lanka who had obtained this certification. There are many organizations providing quality standards and labels in the world. However, it is a highly expensive procedure to develop a farm to the quality standards and to achieve the certification which adds to the challenges in adopting organic agriculture (Lanka Organic Agriculture Movement).

\section{THE CHALLENGES FOR ORGANIC AGRICULTURE}

There are number of evidences to show modern agriculture using / overusing agrochemicals is responsible for environmental pollution. Large amounts of artificial agrochemicals are added to the soil while the contribution of organic matter to the ecosystem had decreased. This led to the pollution of the environment with special reference to water and foods. Some examples of the adverse repercussions are nitrate pollution in drinking water, eutrophication in surface water reservoirs, accumulation of heavy metals ant pesticide residuals in foods etc.

Despite growing awareness of the risks of chemicals and pesticides and possible link to the $\mathrm{CKDu}$, farmers in the CKD affected regions are extremely reluctant to give up the use of agrochemicals. They now have little confidence in traditional agricultural methods of their ancestors. They have been made to believe that the new chemical-industrial approach represents progress and that chemical pesticides are indispensable for their survival. It may not be necessary to dismiss all aspects of industrialized agriculture or attempt to return to pre-modern agriculture. A range of alternatives to the chemical led approach to pest management can be considered. One is Integrated Pest Management (IPM) encouraged by the wellknown international NGO, Care International in Sri Lanka (Care International, 1997; Uggalla, 1997 in IWMI 2012). IPM seeks to maximize the use of safe, cheap, and simple pest control techniques by including organic traditional methods with the safest possible use of chemical pesticides where necessary. Another is Effective Microorganism (EM), a multi-purpose organic fertilizer and pesticide. It has been tried with much success in IPM projects in Sri Lanka including control of the brown hopper, which could not be contained by chemical pesticides (Bandarage, 2013).

Given farmers' fear of economic survival and reluctance to give up chemical inputs, the switch to organic fertilizers and pesticides must involve a gradual process including research, advocacy, and public education. It calls for partnership among farmer producers, consumers, civil society groups, the government, intergovernmental organizations, such as the World Health Organisation and companies that 
are genuinely willing to support sustainable agriculture. Sri Lankan companies can play an important role in developing local organic alternatives to imported agrochemicals and food products, such as milk powder.

\section{ACTIONS TAKEN BY THE GOVERNMENT TOWARDS PROMOTING ORGANIC AGRICULTURE}

With a view to provide a sustainable solution to the above issue, Government of Sri Lanka launched a national programme titled 'Vasa Visa Nethi Ratak (Towards Toxin Free Country) in 2016 with a view to make the country free of poisonous agrochemicals and thereby free of poisoned or polluted food including rice, vegetables and fruits. A three year plan was also launched with milestones to achieve this target. In this Plan the major actions that are to be taken are;

- Discourage the excessive use of agro toxins - increase the efficiency of existing agriculture, reduction of materials harmful to nature, reduction in the use of and regeneration of limited natural resources, reduction of yield costs

- Encourage and use of soil conservation, integrated plant nutrient management and integrated pest management

- Educate farmers on managing plant distances to optimize yield, usage of agrochemicals according to directives, reduction of fertilizer waste, identifying fertilizer application areas to optimize the nutritional impacts on the land, use of improved agricultural equipment, use of improved crop management techniques

- Use of green fertilizers, organic fertilizers, micro biological fertilizers to be used as alternatives to chemical fertilisers

- Improve microbial activity, improve the size of the roots and bushiness of the rice plant
- Use natural alternatives ie nitrogen fixers, plant microbes, live pest controllers, reduced soil preparation

- Use physical/mechanical methods for pest control instead of chemicals ones

- Practice Crop rotation, multi cropping to improve diversity of life on surface as well as in the soil - following an ecosystem approach

\section{REFERENCES}

BANDARAGE A. Political Economy of Epidemic Kidney Disease in Sri Lanka. SAGE Open October - December. 1993; 1-13.

CHANDRAJITH R, DISSANAYAKE CB, ARIYARATHNA T, HERATH HMJMK \& PADMASIRI JP. Dose dependent $\mathrm{Na}$ and $\mathrm{Ca}$ in fluoride rich drinking water - another major cause of chronic renal failure in tropical arid regions. Science of the Total Environment. 2011; 409: 671-675.

CHANDRAJITH R, NANAYAKKARA S, ITALI, S, ATHURALIYA TN, DISSANAYAKE CB, ABEUYSEKERA T, HARADA K, WATANABE T \& KOIZUMI A. Chronic kidney disease of uncertain etiology (CKDUe) in Sri Lanka: geographic distribution and environmental implications. Environmental Geochem Health. 2010; 33 (3): 267-78.

HANDUNNETTI D \& DANIEL S. "Conflicting reports highlight scientific data gaps in Sri Lanka's chronic kidney disease". 2012. Available in http://www.scidev.net/en/southasia/features/con flicting-reports-highlight-scientificdata-gaps-insri-lanka-s-chronic kidney.html. Accessed on $15^{\text {th }}$ Aug 2016.

IFOAM - Organics International Organic 3.0 and TIPI - The next phase for organic agriculture. Accessed on 30 ${ }^{\text {th }}$ Dec 2016

Lanka Organic Agriculture Movement (LOAM). Available in https://www.mesaprogram.org/2012/05/31/sri- 
lanka-lanka-organic-agriculture-movementloam-11309/. Accessed on $2^{\text {nd }} J a n 2016$.

MINISTRY OF HEALTH. National Health Strategic Master Plan. 2016-2015.

NAVAGOVIYA.

Available in http://www.navagoviya.org/index.php?option= com_content $\&$ view $=$ article $\&$ id $=25 \&$ lang $=$ en Accessed on $2^{\text {nd }}$ Jan 2017.

NOBLE A, AMERASINGHE P, MANTHRITHILAKE $\mathrm{H}$ \& ARASALINGAM S. Review of Literature on Chronic Kidney Disease of Unknown Etiology (CKDu) in Sri Lanka. IWMI. 2012; Working Paper 158.

PRESIDENTIAL SECRETARIAT. A Toxin Free National 3 year Plan. 2016.

RANASINGHE H. A Sustainable Solution to Chronic Kidney Disease Unidentified through Organic Agriculture, In: Protect the Kidneys through Enhancing Awareness, Presidential Task Force on Chronic Kidney Disease Unidentified. 2017.

RANASINGHE, $\mathrm{H}$ \& RANASINGHE $\mathrm{M}$. Status, Gaps and Way Forward in Addressing the Chronic Kidney Disease Unidentified (CKDu) in Sri Lanka. Journal of Environmental Professionals Sri Lanka 2015; 4 (2): 58-68.

RANAWEERA S. Development of Organic Agriculture Sector in Sri Lanka. Available in http://www.asiantribune.com/node/10186 Accessed on $2^{\text {nd }}$ Jan 2017.

RODRIGO C. Yield vs. cost: Difference between organic and inorganic farming in Sri Lanka. Available in http://www.ft.lk/article/537472/Yield-vs--cost-Difference-between-organic-and-inorganicfarming-in-Sri-Lanka. Accessed on $5^{\text {th }}$ Sep 2016.

WIMALAWANSA S. Agrochemicals and Chronic Kidney Disease of Multi-factorial origin: An Environmentally induced, occupational exposure disease, International Journal of Nephrology and Kidney Failure. 2015; 1(3): 1-11.

WIMALAWANSA S. Escalating chronic kidney diseases of multi-factorial origin in Sri Lanka: causes, solutions, and recommendations. Environ Health Prev. Med. 2014; 19(6): 375394.

WORLD HEALTH ORGANISATION. International Expert Consultation on Chronic Kidney Disease of Unknown Etiology. 2016 WORLD HEALTH ORGANISATION. Report on CKDu 2012.

WORLD HEALTH ORGANISATION. Working Together for Health. 2006. 